Article

\title{
The Inhibitory Mechanisms Study of 5,6,4'-Trihydroxy-7,3'-Dimethoxyflavone against the LPS-Induced Macrophage Inflammatory Responses through the Antioxidant Ability
}

\author{
Shih-Hao Wang ${ }^{1}$, Chia-Hua Liang ${ }^{2}$, Fong-Pin Liang ${ }^{3}$, Hsiou-Yu Ding ${ }^{4}$, Shiuan-Pey Lin ${ }^{1}$, \\ Guan-Jhong Huang ${ }^{5}$, Wen-Chuan Lin ${ }^{1}$ and Shin-Hun Juang ${ }^{3, *}$ \\ 1 School of Pharmacy, China Medical University, Taichung 404, Taiwan; isaacwangsh@gmail.com (S.-H.W.); \\ splin@mail.cmu.edu.tw (S.-P.L.); wclin@mail.cmu.edu.tw (W.-C.L.) \\ 2 Department of Cosmetic Science, Chia Nan University of Pharmacy and Science, Tainan 717, Taiwan; \\ tinna_ling@mail.cnu.edu.tw \\ 3 Department of Pharmacy, Tajen University, Pingtung 907, Taiwan; ultramarine@seed.net.tw \\ 4 Institute of Cosmetic Science, Chia Nan University of Pharmacy and Science, Tainan 717, Taiwan; \\ hsiou221@yahoo.com.tw \\ 5 Department of Chinese Pharmaceutical Sciences and Chinese Medicine Resources, China Medical University, \\ Taichung 404, Taiwan; gjhuang@mail.cmu.edu.tw \\ * Correspondence: paul.juang@gmail.com; Tel.: +886-8-762-4002 (ext. 2433)
}

Academic Editor: Isabel C. F. R. Ferreira

Received: 2 December 2015 ; Accepted: 18 January 2016 ; Published: 22 January 2016

\begin{abstract}
The whole plant of Anisomeles ovata has been widely used in Taiwan for treating inflammation-related skin and liver diseases, however, the detailed pharmacology mechanisms have yet to be elucidated. In the present study, one of the major components, 5,6,4'-trihydroxy$7,3^{\prime}$-dimethoxyflavone (5-TDMF), was purified from a methanol extract of Anisomeles ovata. A pharmacological study of this compound suggests that 5-TDMF possesses potent free radical scavenging activity both in vitro and ex vivo. Furthermore, 5-TDMF reduces nitric oxide and pro-inflammatory cytokine production in LPC-treated RAW 264.7 cells through the attenuation of nitric oxide synthase and cyclooxygenase-2. Additional experiments suggest that of 5-TDMF interferes with nuclear factor- $\mathrm{kB}$ translocation and mitogen-activated protein kinase pathways. These results identify 5-TDMF as an anti-oxidant and anti-inflammatory compound, explain the pharmacologic function of Anisomeles ovata and suggest its great potential as a new anti-inflammatory remedy.
\end{abstract}

Keywords: Anisomeles ovata; 5,6,4'-trihydroxy-7,3'-dimethoxyflavone; anti-inflammatory; anti-oxidant; reactive oxygen species

\section{Introduction}

Oxidative stress generally occurs when mitochondria overproduce reactive oxygen species (ROS) such as superoxide anion radicals $\left(\mathrm{O}_{2}{ }^{\bullet-}\right)$, hydrogen peroxide $\left(\mathrm{H}_{2} \mathrm{O}_{2}\right)$, and hydroxyl radicals $\left(\mathrm{OH}^{\bullet}\right)$. The production of excess ROS molecules can lead to DNA, RNA, lipid, protein, and enzyme damage. Additionally, high levels of ROS production also leads to the activation of the NF-KB signaling pathway, up-regulation of inducible nitric oxide synthase (iNOS), cyclooxygenase-2 (COX-2) expression and induction of pro-inflammatory cytokines such as tumor necrosis factor-alpha (TNF- $\alpha$ ) and interleukins [1-3]. Clinically, continuous exposures to oxidative damage have been correlated to cardiovascular diseases, diabetes, chronic inflammation and some types of cancer $[4,5]$. Therefore, 
identifying effective blocking agents of ROS production may serve as a potent anti-inflammation and cancer therapeutic.

Anisomeles ovata R. Br, also known as Anisomeles indica Kuntz., is the only species of the Labiatae family found in Taiwan and has been widely used as a herbal remedy to treat inflammation-related liver and skin diseases, hypertension and immune deficiencies [6]. Recent studies have suggested that Anisomeles ovata extracts exert various biological activities, including anti-oxidant, anti-inflammatory and tumor cell proliferation inhibitory [7-10], however, the underlying pharmacological mechanisms are still unclear. In order to identify the active ingredients of Anisomeles ovata, a number of chemical components have been identified, including flavonoids, terpenoids and steroids [9,11-13]. Among the isolated compounds, 5,6,4'-trihydroxy-7,3'-dimethoxyflavone (5-TDMF) was found to be the major flavonoid in the methanol extract of Anisomeles ovata [14]. However, a detailed pharmacological study of 5-TDMF has yet to be reported. In the present study, our results demonstrate that 5-TDMF shows potent free radical scavenging and anti-inflammatory activity without any observable cytotoxicity. Further experimental results also showed that 5-TDMF could block LPS-induced NF-kB translocation and iNOS and COX-2 expressions through inhibition of the mitogen-activated protein (MAP) kinase and Erk signaling pathways. Collectively, our study suggests that 5-TDMF may be a potent new chemopreventive anti-inflammatory agent.

\section{Results}

\subsection{5-TDMF Possesses Weak or no Cytotoxicity toward the Experimental Cell Lines}

To evaluate the cytotoxicity of 5-TDMF, HaCaT, BNLCL2 and RAW 264.7 cells were co-cultured with varying concentrations of 5-TDMF for $72 \mathrm{~h}$ and cell viability was determined by the MTT assay. Our results suggest that 5-TDMF is not cytotoxic to BNLCL2 and RAW 264.7 cells up to $64 \mu \mathrm{M}$. However, at higher concentrations of 5-TDMF, HaCaT proliferation was reduced by less than $30 \%$ (Figure 1B).

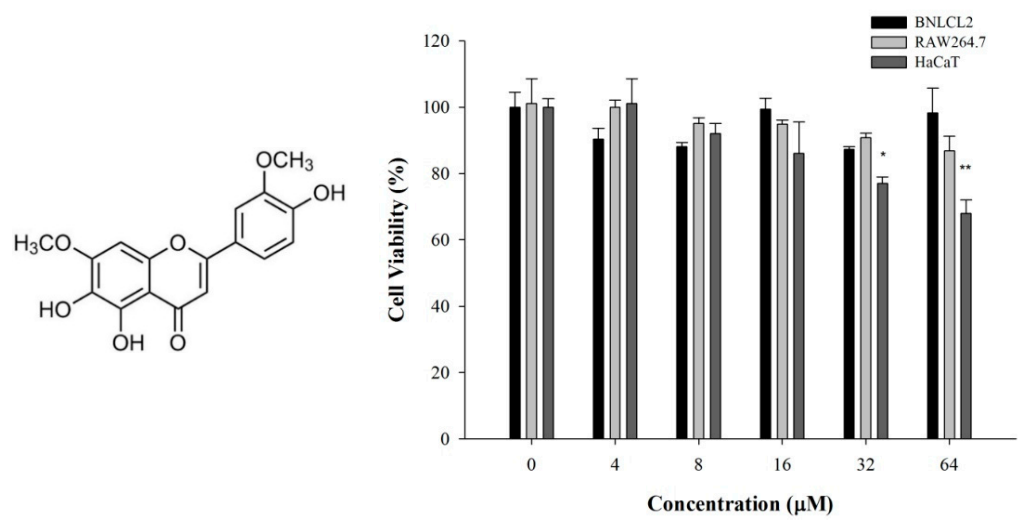

(A)

(B)

Figure 1. The cytotoxicity of 5-TDMF toward human keratinocytic cells (HaCaT), murine macrophage (RAW 264.7) and liver (BNLCL2) cells. (A) Chemical structure of 5-TDMF; (B) Cell viability as measured by an MTT assay after treatment with various concentrations of 5-TDMF for $72 \mathrm{~h}$. The data were analyzed by Student's t-test. Statistical significance is determined by ${ }^{*} p<0.05$ and ${ }^{* *} p<0.01$ relative to control.

\subsection{5-TDMF Demonstrates Potent Inhibitory Activity of Lipid Peroxidation}

Lipid peroxidation (LP) is considered as the main molecular mechanism involved in the oxidative damage of cellular mitochondria and microsomes. In the presence of $\mathrm{OH}^{\bullet}$, lipid peroxyl radicals $\left(\mathrm{LOO}^{\bullet}\right)$ are generated through the reaction of polyunsaturated fatty acids with oxygen. After cells are insulted by $\mathrm{LOO}^{\bullet}$, thiobarbituric acid reactive substances (TBARS) can be generated from the 
breakdown of peroxides and can be used to monitor cellular damage [15]. In this study, the ability of 5-TDMF to protect against LP was evaluated by the degree of reduction of TBARS using liposome and mouse liver homogenate models [16,17]. In the liposome model, our results indicate that the inhibition of LP by 5-TDMF was concentration-dependent, with an $\mathrm{EC}_{50}$ of $4.5 \mu \mathrm{M}$. While low concentrations of 5-TDMF demonstrated weaker LP protection compared to Trolox, at concentrations of $16 \mu \mathrm{M}$ and higher, 5-TDMF displayed comparable LP protective properties as Trolox (Figure 2A). Furthermore, the inhibition of TBARS production in the mouse liver homogenate model by 5-TDMF also showed a concentration-dependent relationship. The inhibitory effects of 5-TDMF reached as high as 60\% when liver cells were co-cultured with $32 \mu \mathrm{M}$ 5-TDMF (Figure 2B). Collectively, our results demonstrate that 5-TDMF possesses similar or better LP inhibitory activity compared to Trolox.

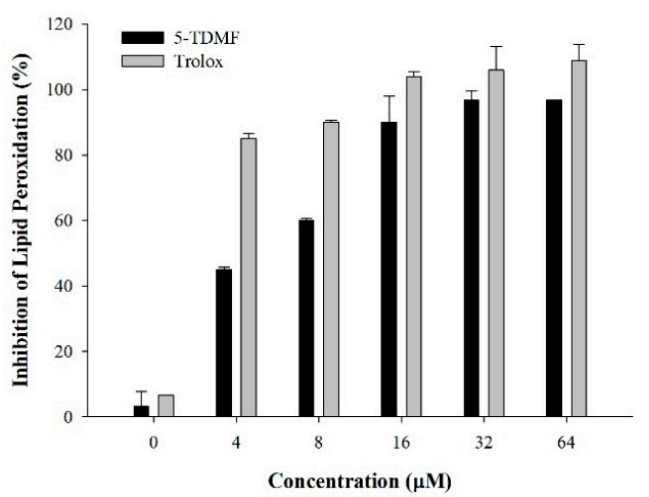

(A)

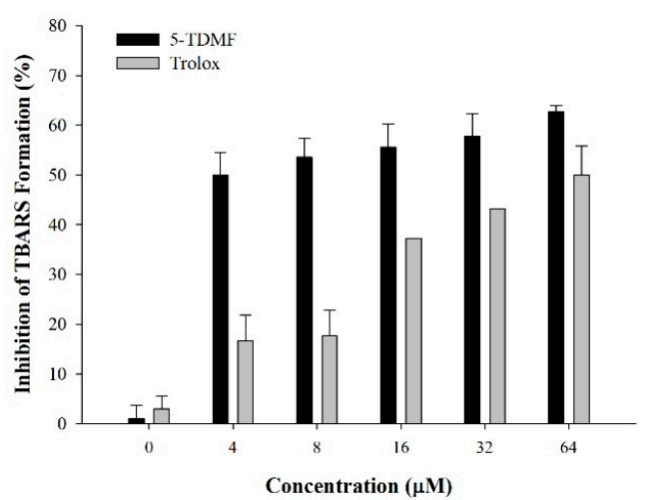

(B)

Figure 2. Inhibition of LP formation by 5-TDMF in (A) the liposome model and (B) mouse liver homogenate model. Varying concentrations of 5-TDMF and Trolox were added into the liposome suspension or mouse liver homogenates using the $\mathrm{Fe}^{2+}$ /ascorbate system and the formation of LP was then measured as described in the materials and method section.

\subsection{5-TDMF is a Potent Free Radical Scavenger and Anti-Oxidant}

In order to examine the LP protective mechanisms of 5-TDMF, several experiments to measure free radical scavenging capabilities were performed. First, the 5-TDMF reductive ability towards two potent radical molecules, $\mathrm{DPPH}^{\bullet}$ and $\mathrm{ABTS}^{\bullet+}$ were measured. Our results showed that 5-TDMF exhibited potent free radical scavenging activity in a concentration-dependent manner with an $\mathrm{EC}_{50}$ value of $26.9 \mu \mathrm{M}$ for $\mathrm{DPPH}^{\bullet}$ and $47.2 \mu \mathrm{M}$ for $\mathrm{ABTS}^{\bullet+}$ (Figure 3A,B), and accordingly, the Trolox equivalent anti-oxidant capacity (TEAC) value derived from the dose-response curve for 5-TDMF was $1.4 \mathrm{mM}$ Trolox/g.

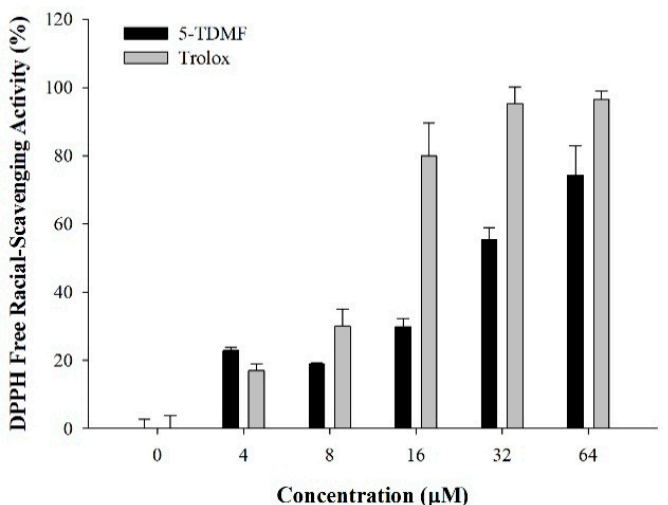

(A)

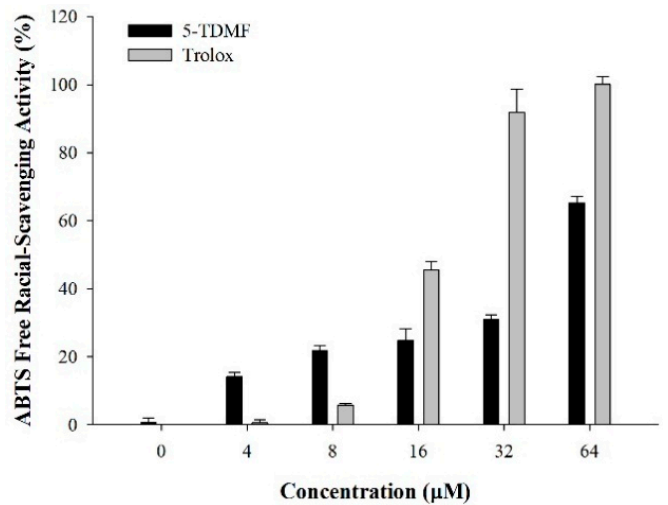

(B)

Figure 3. Cont. 


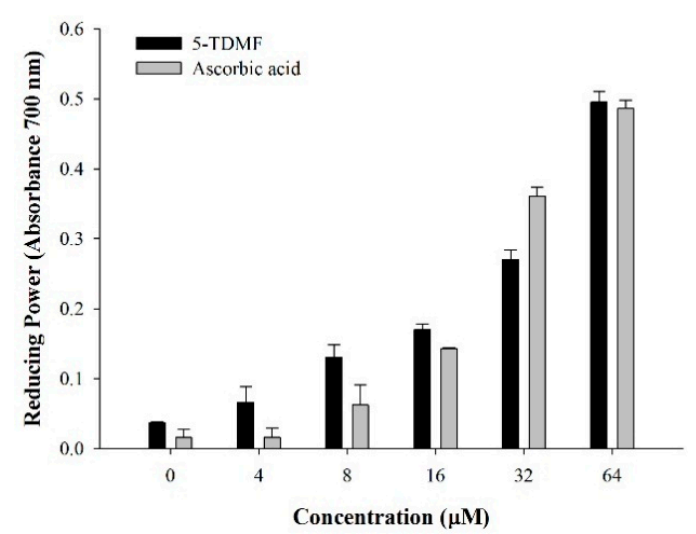

(C)

Figure 3. Evaluation of anti-oxidant activity of 5-TDMF in vitro. Varying concentrations of 5-TDMF and Trolox were added into the reaction buffer of $\mathrm{DPPH}^{\bullet}(\mathbf{A})$ and $\mathrm{ABTS}^{\bullet+}(\mathbf{B})$ and the formation of $\mathrm{DPPH}^{\bullet}$ and $\mathrm{ABTS}^{\bullet+}$ was measured; (C) Reducing power of 5-TDMF and ascorbic acid by the Oyaizu method.

Additionally, a compound's reducing capabilities can be used as an indicator of its potential as an anti-oxidant [5]. Accordingly, the reducing power of 5-TDMF was determined by the Oyaizu method [18]. The results showed that 5-TDMF exhibited significant activity against $\mathrm{Fe}^{2+}$ formation. At low concentrations, 5-TDMF and ascorbic acid have comparable reducing power. However, at mid-range concentrations, $8 \mu \mathrm{M}$ of 5-TDMF was found to be as efficient as $16 \mu \mathrm{M}$ of ascorbic acid (Figure 3C).

\subsection{5-TDMF Showed Potent Cellular Radical-Scavenging Activity by Suppressing the Intracellular ROS Formation and Up-Regulating GSH Expression}

Examining ROS and GSH levels is widely accepted as a measurement of oxidative stress and can be used to monitor the effectiveness of an anti-oxidant intervention strategy. Therefore, the ROS and GSH levels of $\mathrm{H}_{2} \mathrm{O}_{2}$-treated BNLCL2 cells in the presence or absence of 5-TDMF was determined. The results showed that pretreated with 5-TDMF can significantly reduce the levels of ROS in $\mathrm{H}_{2} \mathrm{O}_{2}$-treated BNLCL2 cells with the geometric mean value reduced from 49.6 to 13.2 and 1.5 when cells were pretreated with 32 and $64 \mu \mathrm{M}$ of 5-TDMF, respectively (Figure 4A). Furthermore, our results showed that significant amount of GSH can be resorted, the geometric mean was restored from 54.1 to 67.78 and 81.25 , by pre-treatment of 5-TDMF of 32 and $64 \mu \mathrm{M}$ of 5-TDMF respectively (Figure 4B). NAC, the positive control, reduced the levels of ROS from 49.6 to 0.06 and restored the levels of GSH from 54.1 to 86 .

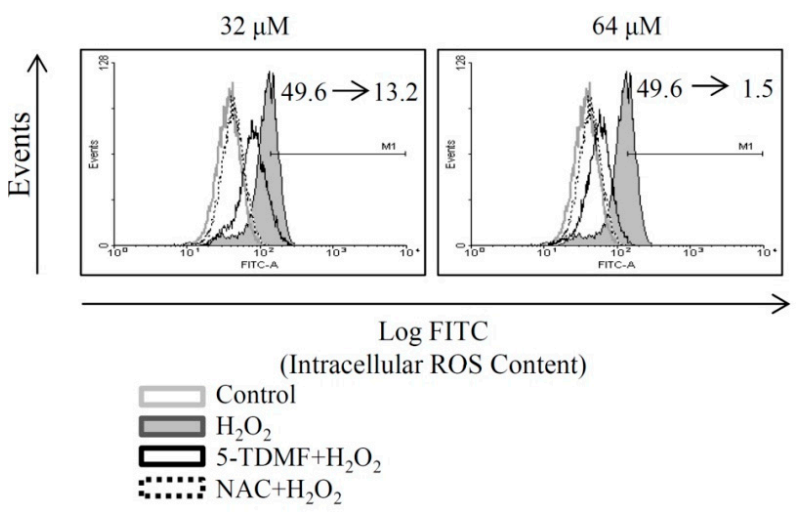

(A)

Figure 4. Cont. 


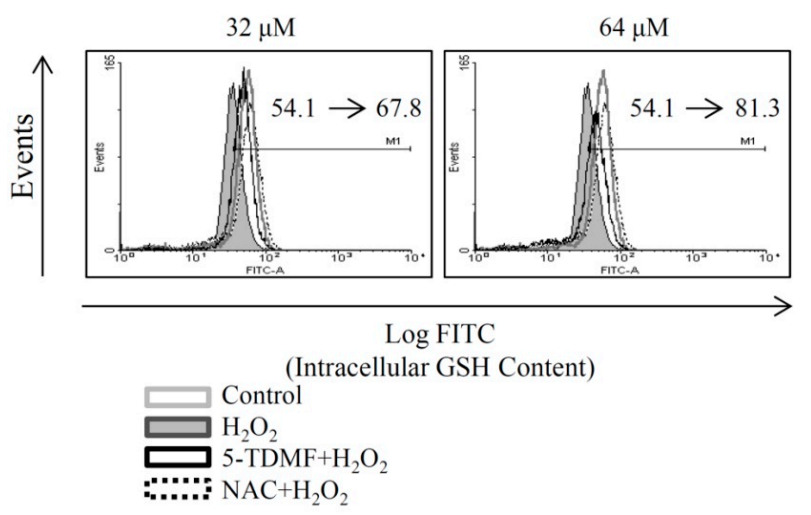

(B)

Figure 4. Evaluation of anti-oxidant activity of 5-TDMF ex vivo. Cells were pretreated with 32 or $64 \mu \mathrm{M}$ 5-TDMF for $24 \mathrm{~h}$ and $\mathrm{H}_{2} \mathrm{O}_{2}(0.1 \mathrm{mM})$ was added for $1 \mathrm{~h}$. The $\mathrm{H}_{2} \mathrm{O}_{2}$-treated cells were collected and ROS (A) and GSH (B) levels were measured as describe in the materials and method section.

These results suggested that 5-TDMF can inhibit ROS formation and GSH expression in cells exposed to $\mathrm{H}_{2} \mathrm{O}_{2}$. Hence, these results suggest that the stronger radical-scavenging capacity of 5-TDMF acts as both primary and secondary anti-oxidants by inhibiting the formation of lipid peroxyl radicals.

\subsection{5-TDMF Reduced LPS-Induced Inflammatory Responses in RAW 264.7 Cells}

LPS stimulation induces inflammatory responses from macrophages resulting in NO and TNF- $\alpha$ up-regulation $[19,20]$. Since Anisomeles ovata has been widely used as an anti-inflammatory herb, we wanted to examine the anti-inflammatory potential of 5-TDMF. The ability of 5-TDMF to inhibit LPS-induced NO production in RAW 264.7 cells was measured by the Griess reagent system [21]. Results showed that NO production in RAW 264.7 cells was increased by LPS treatment, however, pre-treatment with 5-TDMF significantly suppressed LPS-induced NO production with an $\mathrm{EC}_{50}$ value of $9.9 \mu \mathrm{M}$ (Figure 5A). Since previous results showed that 5-TDMF presented no significant cellular toxicity toward RAW 264.7 cells up to $64 \mu \mathrm{M}$, the down-regulation of NO production by 5-TDMF in LPS-treated RAW 264.7 cells was not due to cell death.

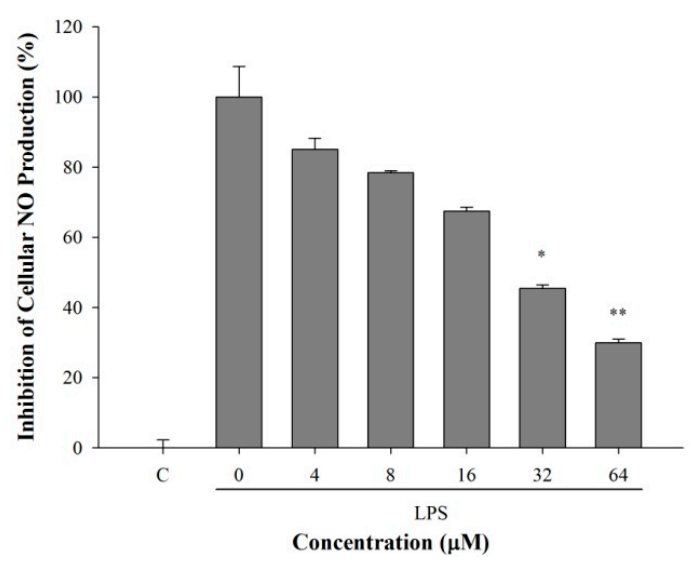

(A)

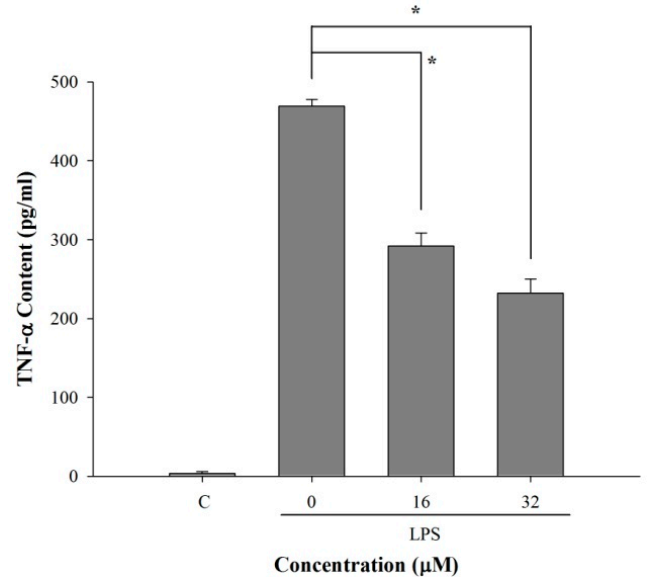

(B)

Figure 5. The anti-inflammatory effects of 5-TDMF towards the LPS-treated RAW 264.7 cells. RAW 264.7 cells were pre-treated with or without 5-TDMF for $12 \mathrm{~h}$. After stimulation with LPS (100 ng/mL), RAW 264.7 cells were co-cultured in the presence or absence of 5-TDMF for $24 \mathrm{~h}$ and the inhibitory effects of 5-TDMF on NO (A) and TNF- $\alpha$ (B) production were measured. ANOVA follows Dunnett's test. Statistical significance is determined by ${ }^{*} p<0.05$ and ${ }^{* *} p<0.01$ relative to LPS. 
Furthermore, the anti-inflammatory activity of 5-TDMF was evaluated toward the LPS-treated RAW264.7 cells. Our results showed that pre-treatment of 5-TDMF suppressed LPS-induced production of TNF- $\alpha$ in RAW 264.7 cells. Compared to the untreated group, the amount of TNF- $\alpha$ found in 5-TDMF-treated (32 $\mu \mathrm{M})$ RAW 264.7 cells was down-regulated by 50\% (Figure 5B). The above results suggested that 5-TDMF can reduce LPS-induced NO and TNF- $\alpha$ production in macrophage cells.

2.6. Pre-Treatment with 5-TDMF Can Suppress LPS-Induced NF-кB and MAP Signaling Pathway Resulting in the Down-Regulation of $i N O S$ and COX-2 Expression

In order to delineate the molecular mechanisms of 5-TDMF mediated down-regulation of NO and TNF- $\alpha$, protein expression levels of two upstream signal proteins iNOS and COX-2, were investigated. Our results showed that LPS-induced iNOS and COX-2 protein in RAW 264.7 cells can be suppressed by pre-treatment with 5-TDMF in a concentration-dependent manner (Figure 6A).

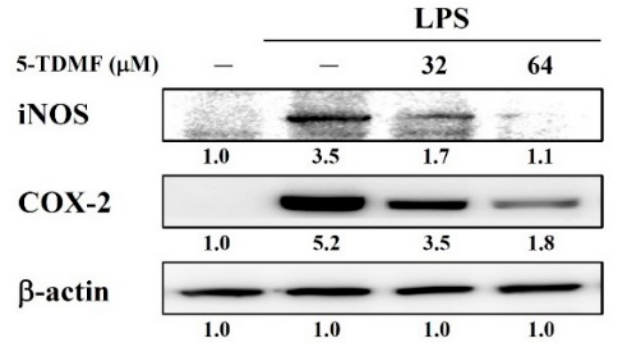

(A)

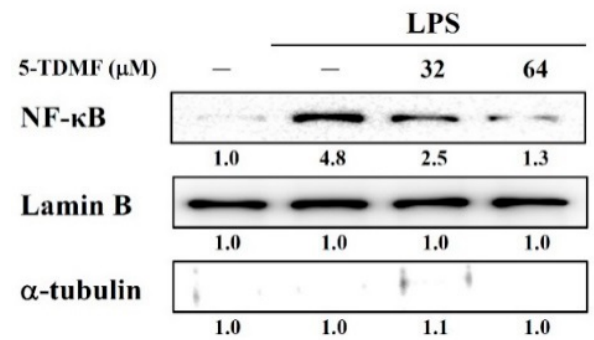

(B)

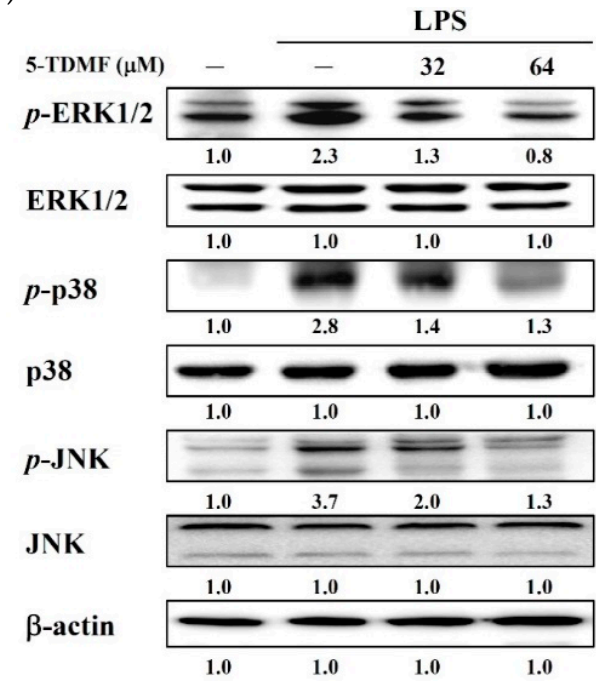

(C)

Figure 6. 5-TDMF inhibits LPS-induced inflammatory responses. The RAW 264.7 cells were pre-treated with or without 5-TDMF for $12 \mathrm{~h}$ and then LPS $(100 \mathrm{ng} / \mathrm{mL})$ for $30 \mathrm{~min}$. iNOS and COX-2 (A); nuclear NF- $\mathrm{B}$ (B) and ERK1/2, p38 and JNK (C) expression were examined by western blot analysis.

Previous studies showed that free radical could up-regulation iNOS and COX-2 expression through activation of NF-kB nuclear translocation [22,23], therefore whether 5-TDMF could interfere NF-кB p65 translocation was investigated. The Western blots results demonstrated that pre-treatment with 5-TDMF can significantly decrease LPS-induced NF- $\mathrm{B}$ p 65 protein nuclear translocation (Figure 6B) without changing the total NF- $\mathrm{BB}$ p65 protein expression levels (data not showed). Furthermore, the level of $p$-ERK1/2, $p$-p38 and $p$-JNK was significantly suppressed in a 5-TDMF concentration-dependent manner (Figure 6C). These results indicate that 5-TDMF suppressed expression of iNOS and COX-2 through inhibition of NF- $\mathrm{B}$ and the down-regulation of the MAP and Erk signaling kinases. 


\section{Discussion}

Oxidative stress typically occurs because of an imbalance between the production of reactive oxygen species (ROS) and anti-oxidants [24]. Oxidative stress can disrupt the DNA and RNA stability, perturb proteins function and induce lipid peroxidation then cause serious cellular damage.

Lipid peroxidation can be described generally as a process whereby oxygen insertion into polyunsaturated fatty acids after attack by free radicals results in lipid peroxyl radicals and hydroperoxides [25]. These highly reactive electrophiles readily react with cellular proteins and nucleic acids initiating signaling cascades and activating transcription factors resulting in inflammation [26].

Recent studies have shown that inflammation can up-regulate many pro-inflammatory mediators such as iNOS and COX-2 [1,27] and these two enzymes are also activated by the key transcription factor NF- $\mathrm{kB}$ resulting in stress responses, inflammation, and apoptosis [28]. In addition, the induction of NF- $\mathrm{KB}$ activity can also be modulated by the MAPK family, including Erk1/2, p38 MAPK and JNK which are known to be involved in various cellular functions [1,29]. Based on these observations, identifying an effective agent to block ROS production may serve as a rational approach to developing novel anti-inflammatory treatments.

The extract of Anisomeles ovata has long been used for the treatment of diverse inflammatory relative skin and liver diseases in Taiwan [9], however, the active ingredients and the molecular mechanisms of the anti-inflammatory activity remained elusive. In the present study, one of the major components of methanol-extracted Anisomeles ovata, 5-TDMF, was isolated and its pharmacological activity evaluated for free radical-scavenging and anti-inflammatory potential.

Our results indicate that 5-TDMF shows very weak cytotoxicity (Figure 1B) but possesses potent inhibitory effects against $\mathrm{Fe}^{3+}$-induced lipid peroxidation and TBARS production (Figure 2A,B). Moreover, a concentration-dependent anti-oxidant activity of 5-TDMF was found against DPPH ${ }^{\bullet}$ and $\mathrm{ABTS}^{\bullet+}$ with the $\mathrm{EC}_{50}$ values of $26.9 \mu \mathrm{M}$ and $47.2 \mu \mathrm{M}$, respectively (Table 1 ) and it showed better reducing power than an equivalent concentration of ascorbic acid (Figure 2C). Furthermore, the protective action of 5-TDMF against $\mathrm{H}_{2} \mathrm{O}_{2}$-induced BNLCL2 cell damage was demonstrated through the reduction of $\mathrm{H}_{2} \mathrm{O}_{2}$-induced ROS production and restored the $\mathrm{H}_{2} \mathrm{O}_{2}$-suppressed GSH expression (Figure 4A,B). Collectively, our results clearly demonstrate the potential multiple anti-oxidative functions of 5-TDMF.

Table 1. The effective concentrations of 5-TDMF in vitro antioxidant assays.

\begin{tabular}{ccccc}
\hline \multirow{2}{*}{ Sample } & Lipid Peroxidation & TBARS Levels & DPPH $^{\bullet}$ & ABTS $^{\bullet+}$ \\
\cline { 2 - 5 } & $\mathrm{EC}_{\mathbf{5 0}}(\mu \mathbf{M})$ & $\mathbf{E C}_{\mathbf{5 0}}(\mu \mathbf{M})$ & EC $_{\mathbf{5 0}}(\mu \mathbf{M})$ & EC $_{\mathbf{5 0}}(\mu \mathbf{M})$ \\
\hline 5-TDMF & 4.5 & 3.0 & 26.9 & 47.2 \\
Trolox & 2.4 & 80.0 & 14 & 21.5 \\
\hline
\end{tabular}

Previous studies showed that ROS could alter the activity of ERKs, p38 and JNKs, and transcription factors which involved in inflammation [3,30]. Therefore, whether the down-regulation of ROS content of 5-TDMF-treatment might be involved in anti-inflammation was investigated. Our results clearly showed that 5-TDMF-treatment reduced LPS-induced NO and TNF- $\alpha$ expression in RAW 264.7 cells (Figure 5A,B). Furthermore, pre-treatment with 5-TDMF inhibited the LPS-induced MAPK/ERK signaling pathway (Figure 6C), suppressed the LPS-induced NF- $\mathrm{kB}$ nuclear translocation (Figure 6B) resulting in down-regulation of iNOS and COX-2 expression (Figure 6A).

In conclusion, our findings suggest that 5-TDMF possesses potent reducing ability, free radical scavenge activity and an ability to restore GSH expression under the ROS environment. The reduction of cellular ROS accumulation following 5-TDMF treatment could protect lipid peroxidation and reduce LPS-activated MAP kinase and NF- $\mathrm{kB}$ signaling pathways. The reduction of LPS-induced NF- $\mathrm{KB}$ activation could further block ROS-induced inflammation respond (Figure 7). Our results provide strong mechanistic evidence to explain the anti-inflammatory properties of Anisomeles ovata, 
in particular, 5-TDMF as a potent anti-inflammatory compound worthy of further development. The pharmacological activities of additional Anisomeles ovata extracts are also active investigations in our laboratory.

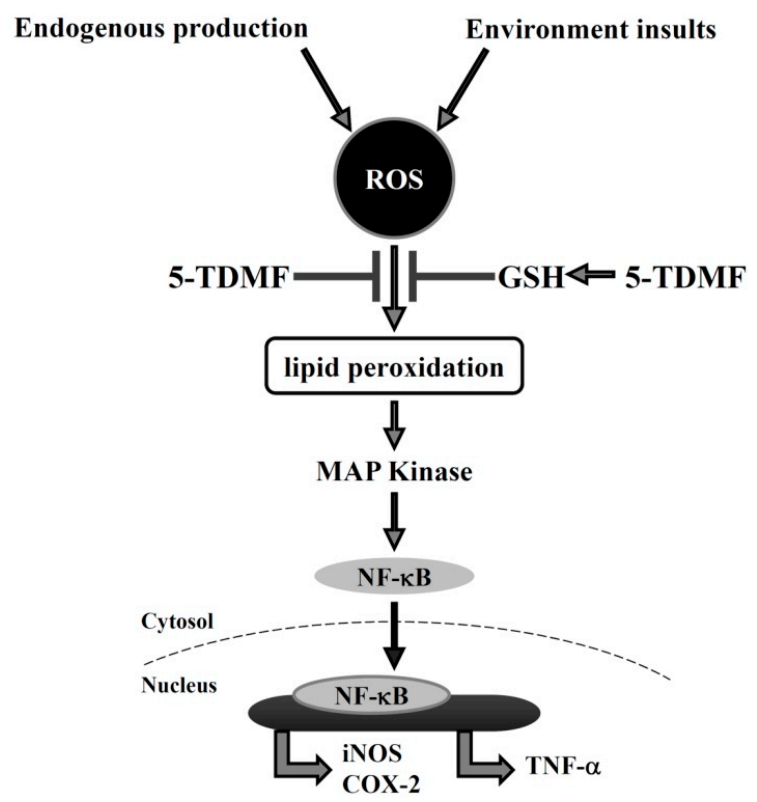

Figure 7. Possible molecular mechanisms underlying the anti-inflammatory activities of 5-TDMF.

\section{Materials and Methods}

\subsection{Isolation of 5-TDMF from the Whole Plant of Anisomeles Ovata}

The 5-TDMF used in this study was purified as a yellow power from the methanol-fraction of Anisomeles ovata by our team following the published procedure [14]. The purified 5-TDMF exhibited similar spectroscopic data (IR, NMR, MS) to a previous publication [31]. In the study, 5-TDMF was dissolved in dimethyl sulfoxide (DMSO) and the final DMSO concentration did not exceed $0.1 \%$.

\subsection{Cell Culture}

Human keratinocytic cells HaCaT were kindly provided by Prof. Hamm-Ming Sheu (National Cheng Kung University Medical College, Tainan, Taiwan). Murine normal embryonic liver BNLCL2 and Murine monocyte-macrophage RAW 264.7 cells were purchased from the Bioresource Collection and Research Center (BCRC 60180 and BCRC 60001, Hsinchu, Taiwan). Cells were cultured in Dulbecco's Modified Eagle Medium (DMEM) medium supplemented with 10\% fetal bovine serum at $37^{\circ} \mathrm{C}$ in a humidified atmosphere of $5 \% \mathrm{CO}_{2}$ in the presence of penicillin/streptomycin and L-glutamine.

\subsection{Chemicals and Reagents}

1,1-Diphenyl-2-picrylhydrazyl (DPPH`), 2,2'-azinobis (3-ethylbenzothiazoline-6-sulphonic acid) diammonium salt $\left(\mathrm{ABTS}^{\bullet+}\right.$ ), 2,5,7,8-tetramethylchromancarboxylic acid (Trolox), 2-thiobarbituric acid (TBA), ascorbic acid, lipopolysaccharide (LPS), $N$-(1-naphthyl)ethylenediamine, sulfanilamide, ethylene diaminetetraacetic acid disodium salt dehydrate (EDTA), hydrogen peroxide $\left(\mathrm{H}_{2} \mathrm{O}_{2}\right)$, trichloracetic acid (TCA), N-acetyl-L-cysteine (NAC) and Trolox were purchased from Sigma Chemical Co. (St. Louis, MO, USA). The 3-(2-pyridyl)-5,6-diphenyl- 1,2,4-triazine- $4^{\prime}, 4^{\prime \prime}$-disulphonic acid monosodium salt (ferrozine) was purchased from Fluka (Buchs, Switzerland). All the chemicals were analytical grade or higher. Primary antibody to $\alpha$-tubulin was purchased from Sigma-Aldrich LLC; antibodies against COX-2, iNOS, $p$-ERK, $p$-JNK, $p$-p38, lamin B, NFKB p65 and $\beta$-actin, as 
well as horseradish peroxidase-conjugated secondary antibody were purchased from Santa Cruz Biotechnology (Santa Cruz, CA, USA).

\subsection{Assessment of Cell Viability}

The colorimetric assay for cellular growth and survival was performed as described by Hansen et al. with modifications (Hansen, Nielsen, and Berg, [32]). Briefly, HaCaT, BNLCL2 and RAW 264.7 cells $\left(1.5 \times 10^{4}\right.$ cells / well $)$ were seeded in 96-well plates overnight and various concentrations of 5-TDMF was added for an additional $72 \mathrm{~h}$. Two hours before the end of the incubation, 3-(4,5-cimethylthiazol-2-yl)-2,5-diphenyltetrazolium bromide (MTT) was added to a final concentration of $5 \mu \mathrm{g} / \mathrm{mL}$. Afterwards, solubilization buffer $\left(40 \%\right.$ DMF and $20 \%$ SDS in $\left.\mathrm{H}_{2} \mathrm{O}\right)$ was added to wells to dissolve violet formazan precipitation overnight at $37^{\circ} \mathrm{C}$. The absorbance at $570 \mathrm{~nm}$ was then detected by a microplate reader and the $\mathrm{IC}_{50}$ value was calculated by linear regression analysis.

\subsection{Free radical Scavenging Activity}

The free radical scavenging activity of 5-TDMF toward $\mathrm{DPPH}^{\bullet}$ and $\mathrm{ABTS}^{\bullet+}$ was measured as previously published $[33,34]$. Various concentrations of 5-TDMF or Trolox were added to the $\mathrm{DPPH}{ }^{\bullet}$ $(0.1 \mathrm{mM})$ or $\mathrm{ABTS}^{\bullet+}$ solution and incubation conditions were performed as previously published [5]. For the $\mathrm{DPPH}^{\bullet}$ assay, the absorbance (A) at $517 \mathrm{~nm}$ was measured after a $30 \mathrm{~min}$ incubation in the dark. For the $\mathrm{ABTS}^{\bullet+}$ assay, the absorbance (A) at $734 \mathrm{~nm}$ was measured after a $30 \mathrm{~min}$ incubation in the dark at $30^{\circ} \mathrm{C}$. Trolox was taken as standard antioxidants. Free radical scavenging activity was calculated based on the following formula: $\left.(\%)=(1) \mathrm{A}_{\text {sample }} / \mathrm{A}_{\text {control }}\right) \times 100$. The $\mathrm{DPPH}^{\bullet}$ and $\mathrm{ABTS}^{\bullet+}$ radical scavenging activities were calculated while $\mathrm{EC}_{50}$ values were estimated using a linear regression algorithm. The material concentration showing the same percentage change of absorbance of the $\mathrm{ABTS}^{\bullet+}$ as that of $1 \mathrm{mM}$ Trolox was defined as Trolox equivalent anti-oxidant capacity (TEAC). The data are presented as mean values \pm standard deviation $(n=3)$.

\subsection{Reducing Power}

The Oyaizu method [18] was used to determine the reducing power of 5-TDMF. Briefly, various concentrations of 5-TDMF or ascorbic acid $(0.2 \mathrm{~mL})$ were added to a mixture of sodium phosphate buffer/potassium ferricyanide $\left(\mathrm{K}_{3} \mathrm{Fe}(\mathrm{CN})_{6}\right)$ solution and incubated at $50{ }^{\circ} \mathrm{C}$ for $20 \mathrm{~min}$. The reaction was stop by adding $0.5 \mathrm{~mL} 10 \%$ TCA $(10 \%, w / v)$ then subjected to centrifugation at $10,000 \mathrm{~g}$ for $10 \mathrm{~min}$. The supernatant was then mixed with ferric chloride $\left(\mathrm{FeCl}_{3}\right)(0.1 \%, w / v)$ solution at room temperature. Ascorbic acid was taken as standard antioxidants. The reducing power was measured as the formation of complexes with $\mathrm{Fe}^{2+}$ at an absorbance of $700 \mathrm{~nm}$.

\subsection{Inhibition of Lipid Peroxidation Formation}

Lipid peroxidation was determined using the liposome model as biological membranes as previously described [33,34]. As a model system of biological membranes, the commercial preparation of liposomes, $\mathrm{pH}$ 5-7, was used. The liposomes, 225-250 nm in diameter, were obtained by dissolving the commercial preparation in demineralized water (1:10) in an ultrasonic bath. For measuring liposome peroxidation formation, $32 \mu \mathrm{L}$ liposome suspensions were incubated with $11 \mu \mathrm{L}$ of $10 \mathrm{mM} \mathrm{FeSO}$, $11 \mu \mathrm{L}$ of $10 \mathrm{mM}$ ascorbic acid in the presence or absence of various concentration of 5-TDMF or Trolox in $1.515 \mathrm{~mL}$ of $50 \mathrm{mM} \mathrm{Na} \mathrm{HPO}_{4}-\mathrm{NaH}_{2} \mathrm{PO}_{4}$ buffer, $\mathrm{pH} 7.4$ (2.5 mL final solution) for $1 \mathrm{~h}$ at $37{ }^{\circ} \mathrm{C}$. The reaction was terminated by adding a cocktail of $0.8 \mathrm{~mL}$ of $1 \%$ 2-thiobarbituric acid and $10 \%$ trichloroacetic acid reagent and $106 \mu \mathrm{L}$ of $0.1 \mathrm{M}$ EDTA at $100{ }^{\circ} \mathrm{C}$ for $20 \mathrm{~min}$. After cooling and centrifugation $(2600 \mathrm{~g}$ for $10 \mathrm{~min})$, malonaldehyde formation was measured at $532 \mathrm{~nm}$. Trolox was taken as standard antioxidants. The percentage of inhibition of lipid peroxidation $=\left(1-\mathrm{A}_{\text {sample }} / \mathrm{A}_{\text {control }}\right) \times 100$ was calculated, and $\mathrm{EC}_{50}$ values were determined. The data are presented as mean values \pm standard deviation $(n=3)$. 


\subsection{Inhibition of Thiobarbituric Acid-Reactive Substances Formation}

Lipid peroxides formation of liver tissues was measured as the formation of TBARS following the Chou's method [17]. Seven-week-old male Institute of Cancer Research (ICR) mice (National Animal Laboratory Center, Taipei, Taiwan) weighing 30-35 g were used. Tissue lipid peroxides produced were monitored by measuring concentrations of TBARS. In brief, liver tissues were homogenized with a Polytron in ice-cold Tris- $\mathrm{HCl}$ buffer $(40 \mathrm{mM}, \mathrm{pH} 7.4)$ to produce a 1:1 $(w / v)$ tissue homogenate, which was centrifuged at $3000 \mathrm{~g}$ for $10 \mathrm{~min}$. $100 \mu \mathrm{L}$ of supernatant was incubated with various concentration of 5-TDMF or Trolox $(200 \mu \mathrm{L})$ in the presence of $\mathrm{FeSO}_{4}(10 \mu \mathrm{M}, 100 \mu \mathrm{L})$ and ascorbic acid $(0.1 \mathrm{mM}, 100 \mu \mathrm{L})$ at $37^{\circ} \mathrm{C}$ for $1 \mathrm{~h}$. The reaction was terminated by the addition of TCA $(28 \% w / v$, $500 \mu \mathrm{L})$, followed by TBA $(1 \% w / v, 380 \mu \mathrm{L})$, and the mixture was then heated at $80{ }^{\circ} \mathrm{C}$ for $20 \mathrm{~min}$. After centrifugation at $3000 \mathrm{~g}$ for $10 \mathrm{~min}$, the TBARS that formed in the supernatant was measured by absorbance at $532 \mathrm{~nm}$. Trolox was taken as standard antioxidants. The inhibition ratio (\%) was calculated by using the following formula: inhibition ratio $(\%)=\left(1-\mathrm{A}_{\text {sample }} / \mathrm{A}_{\text {control }}\right) \times 100$.

\subsection{Measurement of Reactive Oxygen Species and Glutathione Production}

The ROS inhibitory activity of 5-TDMF was measured as described by Bass [35]. The BNLCL2 Cells $\left(1 \times 10^{5}\right.$ cells $/ \mathrm{mL}$ ) were co-cultured with or without 5 -TDMF (32 and $\left.64 \mu \mathrm{M}\right)$ for $24 \mathrm{~h}$. NAC was taken as positive control. After incubation, $0.1 \mathrm{mM} \mathrm{H}_{2} \mathrm{O}_{2}$ was added and the mixture was incubated at $37^{\circ} \mathrm{C}$ for $1 \mathrm{~h}$ then culture medium was replaced with fresh medium containing $10 \mu \mathrm{M}$ DCFH-DA. After 30 min of incubation at $37^{\circ} \mathrm{C}$, fluorescence intensities of DCF were measured on a Canto II flow cytometer (BD Biosciences, San Jose, CA, USA). To measure the 5-TDMF-induced GSH levels, the o-phthalaldehyde (OPA) conversion method by Senft was used [36]. $50 \mu \mathrm{g} / \mathrm{mL}$ of OPA in $0.1 \mathrm{M}$ $\mathrm{Na}_{2} \mathrm{HPO}_{4}-5 \mathrm{mM}$ EDTA buffer was added to the 5-TDMF-treated cells and the reaction was kept in the dark at $25^{\circ} \mathrm{C}$ for $1 \mathrm{~h}$. After two wash steps with phosphate buffer ( $\mathrm{pH} 7.0$ ), the intensity of GSH fluorescence was analyzed on a Canto II flow cytometer (BD Biosciences).

\subsection{Measurements of LPS-Induced NO Production and Inflammatory Cytokines Production}

The Griess reaction [21] was used to measure the production of NO. RAW 264.7 cells were seeded at a density of $1 \times 10^{4}$ cells/well in 96 well-plates. After $24 \mathrm{~h}$, cells were pretreated with various concentrations of 5-TDMF for $12 \mathrm{~h}$ and then $100 \mathrm{ng} / \mathrm{mL}$ LPS was added for another $24 \mathrm{~h}$. At the end of incubation, $0.1 \mathrm{~mL}$ of supernatant from each sample was incubated with the same volume of Griess reagent and the NO production was measured at $540 \mathrm{~nm}$. The inhibition of NO production was calculated using the following inhibition rate formula: $(\%)=\left(1 \mathrm{~A}_{\text {sample }} / \mathrm{A}_{\text {control }}\right) \times 100$ and the results were expressed as $\mathrm{IC}_{50}$ values, which were defined as the concentration that inhibit $50 \%$ of NO production.

To measure the amounts of LPS-induced TNF- $\alpha$ in the cell culture supernatant, Mouse TNF (Mono/Mono) ELISA Set from BD Biosciences were used following the manufacturer's instructions.

\subsection{Preparation of Cell Lysates and Western Blot Analysis}

RAW 264.7 cells were seeded at $5 \times 10^{5}$ cells in a $10 \mathrm{~cm}$ plates overnight and pretreated with $32 \mu \mathrm{M}$ of 5-TDMF for $12 \mathrm{~h}$. A final concentration of $100 \mathrm{ng} / \mathrm{mL}$ of LPS was added into 5-TDMF-pre-treated cells for a pre-determined period. To collect the total cellular protein, cells were collected, lysed in ice-cold lysis buffer (100 mM Tris (pH 7.4), 1\% NP40, 0.01\% SDS, $1 \mathrm{mM} \mathrm{PMSF,} 10 \mu \mathrm{g} / \mathrm{mL}$ pepstatin, and $30 \mu \mathrm{g} / \mathrm{mL}$ leupeptin), and subjected to centrifugation to remove the insoluble material. To analysis the level of nuclear NF- $\kappa$ B, the nuclear and cytoplasmic proteins were separated by a NE-PER ${ }^{\mathrm{TM}}$ Nuclear and Cytoplasmic Extraction Reagents kit (Thermo Scientific ${ }^{\mathrm{TM}}$, Waltham, MA, USA).

Protein concentrations of lysates were determined using the BCA Protein Assay Reagent (Pierce Biotechnology, Rockford, IL, USA). Equal amounts of protein from each sample was separated on a SDS-PAGE gels and transferred to PVDF-membranes. After soaking in a blocking solution consisting 
of TBS with $0.05 \%$ Tween 20 , and $5 \%$ skim milk, the blot was incubated with the primary antibody and antibody binding was detected using the appropriate secondary antibody coupled with horseradish peroxidase according to the manufacturer's instructions. Enhanced chemiluminescence was used to detect the relevant proteins following protocols suggested by the manufacturer and then images were taken on a LAS-4000 (Fuji Film, Tokyo, Japan).

\subsection{Statistical Analysis}

Each experiment was repeated at least three times and the data was expressed as means with standard deviations (SD). Statistical differences were estimated by one-way analysis of variance (ANOVA) following Dunnett's test. $p$-Value less than 0.05 was considered as statistically significant.

Acknowledgments: This research was supported by Ministry of Science and Technology of the Republic of China (NSC 101-2320-B-039-011 and MOST 102-2628-B-127-001-MY3).

Author Contributions: Shin-Hun Juang made contributions to conception, design of the study and revision of the manuscript. Chia-Hua Liang, Fong-Pin Liang, Hsiou-Yu Ding, Shiuan-Pey Lin, Guan-Jhong Huang, Wen-Chuan Lin performed the experimental work and data analysis. Shih-Hao Wang performed the experimental work, interpreted data and formulated the article.

Conflicts of Interest: The authors declare no conflict of interest.

\section{References}

1. Gao, Y.; Jiang, W.; Dong, C.; Li, C.; Fu, X.; Min, L.; Tian, J.; Jin, H.; Shen, J. Anti-inflammatory effects of sophocarpine in LPS-induced RAW 264.7 cells via NF-kappab and mapks signaling pathways. Toxicol. In Vitro 2012, 26, 1-6. [CrossRef] [PubMed]

2. Zeng, K.W.; Yu, Q.; Liao, L.X.; Song, F.J.; Lv, H.N.; Jiang, Y.; Tu, P.F. Anti-neuroinflammatory effect of MC13, a novel coumarin compound from condiment murraya, through inhibiting lipopolysaccharide-induced TRAF6-TAK1-NF-kappab, p38/ERK mapks and Jak2-Stat1/Stat3 pathways. J. Cell. Biochem. 2015, 116, 1286-1299. [CrossRef] [PubMed]

3. Bickers, D.R.; Athar, M. Oxidative stress in the pathogenesis of skin disease. J. Investig. Dermatol. 2006, 126, 2565-2575. [CrossRef] [PubMed]

4. Barreira, J.C.; Ferreira, I.C.; Oliveira, M.B.; Pereira, J.A. Antioxidant activity and bioactive compounds of ten portuguese regional and commercial almond cultivars. Food Chem. Toxicol. 2008, 46, 2230-2235. [CrossRef] [PubMed]

5. Liang, C.H.; Chan, L.P.; Ding, H.Y.; So, E.C.; Lin, R.J.; Wang, H.M.; Chen, Y.G.; Chou, T.H. Free radical scavenging activity of 4-(3,4-dihydroxybenzoyloxymethyl)phenyl-O-beta-D-glucopyranoside from origanum vulgare and its protection against oxidative damage. J. Agric. Food Chem. 2012, 60, 7690-7696. [CrossRef] [PubMed]

6. Huang, T.C.; Hsieh, C.F.; Boufford, D.E.; Kuoh, C.S.; Ohashi, H.; Peng, C.I.; Tsai, J.L.; Yang, K.C.; Hsiao, A.; Tsai, J.M.E. Floraoftaiwan, 2nd ed.; National Science Council of the Republic of China: Taipei, Taiwan, 2003; pp. 437-488.

7. Hsieh, S.C.; Fang, S.H.; Rao, Y.K.; Tzeng, Y.M. Inhibition of pro-inflammatory mediators and tumor cell proliferation by anisomeles indica extracts. J. Ethnopharmacol. 2008, 118, 65-70. [CrossRef] [PubMed]

8. Hou, Y.Y.; Wu, M.L.; Hwang, Y.C.; Chang, F.R.; Wu, Y.C.; Wu, C.C. The natural diterpenoid ovatodiolide induces cell cycle arrest and apoptosis in human oral squamous cell carcinoma Ca9-22 cells. Life Sci. 2009, 85, 26-32. [CrossRef] [PubMed]

9. Rao, Y.K.; Fang, S.H.; Hsieh, S.C.; Yeh, T.H.; Tzeng, Y.M. The constituents of anisomeles indica and their anti-inflammatory activities. J. Ethnopharmacol. 2009, 121, 292-296. [CrossRef] [PubMed]

10. Huang, H.C.; Lien, H.M.; Ke, H.J.; Chang, L.L.; Chen, C.C.; Chang, T.M. Antioxidative characteristics of anisomeles indica extract and inhibitory effect of ovatodiolide on melanogenesis. Int. J. Mol. Sci. 2012, 13, 6220-6235. [CrossRef] [PubMed]

11. Liao, Y.F.; Rao, Y.K.; Tzeng, Y.M. Aqueous extract of anisomeles indica and its purified compound exerts anti-metastatic activity through inhibition of NF-kappab/AP-1-dependent MMP-9 activation in human breast cancer MCF-7 cells. Food Chem. Toxicol. 2012, 50, 2930-2936. [CrossRef] [PubMed] 
12. Chen, Y.L.; Lan, Y.H.; Hsieh, P.W.; Wu, C.C.; Chen, S.L.; Yen, C.T.; Chang, F.R.; Hung, W.C.; Wu, Y.C. Bioactive cembrane diterpenoids of anisomeles indica. J. Nat. Prod. 2008, 71, 1207-1212. [CrossRef] [PubMed]

13. Lien, H.M.; Wang, C.Y.; Chang, H.Y.; Huang, C.L.; Peng, M.T.; Sing, Y.T.; Chen, C.C.; Lai, C.H. Bioevaluation of anisomeles indica extracts and their inhibitory effects on helicobacter pylori-mediated inflammation. J. Ethnopharmacol. 2013, 145, 397-401. [CrossRef] [PubMed]

14. Chang, T.L.; Ding, H.Y.; Teng, K.N.; Fang, Y.C. 5,6,3' $4^{\prime}$-Tetrahydroxy-7-methoxyflavone as a novel potential proteasome inhibitor. Planta Med. 2010, 76, 987-994. [CrossRef] [PubMed]

15. Ashokkumar, P.; Sudhandiran, G. Protective role of luteolin on the status of lipid peroxidation and antioxidant defense against azoxymethane-induced experimental colon carcinogenesis. Biomed. Pharmacother. 2008, 62, 590-597. [CrossRef] [PubMed]

16. Mimica-Dukic, N.; Bozin, B.; Sokovic, M.; Simin, N. Antimicrobial and antioxidant activities of melissa officinalis 1. (lamiaceae) essential oil. J. Agric. Food Chem. 2004, 52, 2485-2489. [CrossRef] [PubMed]

17. Chou, T.H.; Ding, H.Y.; Hung, W.J.; Liang, C.H. Antioxidative characteristics and inhibition of alpha-melanocyte-stimulating hormone-stimulated melanogenesis of vanillin and vanillic acid from origanum vulgare. Exp. Dermatol. 2010, 19, 742-750. [CrossRef] [PubMed]

18. Oyaizu, M. Studies on products of browning reaction-Antioxidative activities of products of browning reaction prepared from glucosamine. Jpn. J. Nutr. 1986, 44, 307-315. [CrossRef]

19. Korhonen, R.; Lahti, A.; Kankaanranta, H.; Moilanen, E. Nitric oxide production and signaling in inflammation. Curr. Drug Targets Inflamm. Allergy 2005, 4, 471-479. [CrossRef] [PubMed]

20. Gwon, W.G.; Lee, M.S.; Kim, J.S.; Kim, J.I.; Lim, C.W.; Kim, N.G.; Kim, H.R. Hexane fraction from sargassum fulvellum inhibits lipopolysaccharide-induced inducible nitric oxide synthase expression in RAW 264.7 cells via nf-kappab pathways. Am. J. Chin. Med. 2013, 41, 565-584. [CrossRef] [PubMed]

21. Green, L.C.; Wagner, D.A.; Glogowski, J.; Skipper, P.L.; Wishnok, J.S.; Tannenbaum, S.R. Analysis of nitrate, nitrite, and [ $n$-15]-labeled nitrate in biological-fluids. Anal. Biochem. 1982, 126, 131-138. [CrossRef]

22. Rajapakse, N.; Kim, M.M.; Mendis, E.; Kim, S.K. Inhibition of inducible nitric oxide synthase and cyclooxygenase-2 in lipopolysaccharide-stimulated RAW264.7 cells by carboxybutyrylated glucosamine takes place via down-regulation of mitogen-activated protein kinase-mediated nuclear factor-kappab signaling. Immunology 2008, 123, 348-357. [PubMed]

23. Kumar, K.J.S.; Hsieh, H.W.; Wang, S.Y. Anti-inflammatory effect of lucidone in mice via inhibition of NF-kappaB/MAP kinase pathway. Int. Immunopharmacol. 2010, 10, 385-392. [CrossRef] [PubMed]

24. Durackova, Z. Some current insights into oxidative stress. Physiol. Res. 2010, 59, 459-469. [PubMed]

25. Ayala, A.; Munoz, M.F.; Arguelles, S. Lipid peroxidation: Production, metabolism, and signaling mechanisms of malondialdehyde and 4-hydroxy-2-nonenal. Oxid. Med. Cell. Longev. 2014, 2014, 360438. [CrossRef] [PubMed]

26. Yadav, U.C.; Ramana, K.V. Regulation of NF-kappaB-induced inflammatory signaling by lipid peroxidation-derived aldehydes. Oxid. Med. Cell. Longev. 2013, 2013, 690545. [CrossRef] [PubMed]

27. Park, S.Y.; Lim, S.S.; Kim, J.K.; Kang, I.J.; Kim, J.S.; Lee, C.; Kim, J.; Park, J.H. Hexane-ethanol extract of glycyrrhiza uralensis containing licoricidin inhibits the metastatic capacity of DU145 human prostate cancer cells. Br. J. Nutr. 2010, 104, 1272-1282. [CrossRef] [PubMed]

28. Gloire, G.; Legrand-Poels, S.; Piette, J. NF-kappaB activation by reactive oxygen species: Fifteen years later. Biochem. Pharmacol. 2006, 72, 1493-1505. [CrossRef] [PubMed]

29. Granado-Serrano, A.B.; Martin, M.A.; Bravo, L.; Goya, L.; Ramos, S. Quercetin attenuates tnf-induced inflammation in hepatic cells by inhibiting the NF-kappaB pathway. Nutr. Cancer 2012, 64, 588-598. [CrossRef] [PubMed]

30. Son, Y.; Cheong, Y.K.; Kim, N.H.; Chung, H.T.; Kang, D.G.; Pae, H.O. Mitogen-activated protein kinases and reactive oxygen species: How can ros activate mapk pathways? J. Signal Transduct. 2011, 2011, 792639. [CrossRef] [PubMed]

31. Voirin, B.; Viricel, M.R.; Favre-Bonvin, J.; van den Broucke, C.O.; Lemli, J. 5,6,4'-trihydroxy-7, 3'-dimethoxyflavone and other methoxylated flavonoids isolated from thymus satureiodes. Planta Med. 1985, 51, 523-525. [CrossRef] [PubMed]

32. Hansen, M.B.; Nielsen, S.E.; Berg, K. Re-examination and further development of a precise and rapid dye method for measuring cell-growth cell kill. J. Immunol. Methods 1989, 119, 203-210. [CrossRef] 
33. Ding, H.Y.; Chou, T.H.; Liang, C.H. Antioxidant and antimelanogenic properties of rosmarinic acid methyl ester from origanum vulgare. Food Chem. 2010, 123, 254-262. [CrossRef]

34. Re, R.; Pellegrini, N.; Proteggente, A.; Pannala, A.; Yang, M.; Rice-Evans, C. Antioxidant activity applying an improved ABTS radical cation decolorization assay. Free Radic. Biol. Med. 1999, 26, 1231-1237. [CrossRef]

35. Bass, D.A.; Parce, J.W.; Szejda, P.; Seeds, M.C.; Thomas, M.; Dechatelet, L.R. Flow cytometric studies of oxidative product formation by neutrophils-A graded response to membrane stimulation. J. Reticuloendoth. Soc. 1982, 32, 79.

36. Senft, A.P.; Dalton, T.P.; Shertzer, H.G. Determining glutathione and glutathione disulfide using the fluorescence probe o-phthalaldehyde. Anal. Biochem. 2000, 280, 80-86. [CrossRef] [PubMed]

Sample Availability: $20 \mathrm{mM}$ stock solution of 5-TDMF in DMSO is available from authors upon request.

(C) 2016 by the authors; licensee MDPI, Basel, Switzerland. This article is an open access article distributed under the terms and conditions of the Creative Commons by Attribution (CC-BY) license (http:/ / creativecommons.org/licenses/by/4.0/). 